This item was submitted to Loughborough's Research Repository by the author.

Items in Figshare are protected by copyright, with all rights reserved, unless otherwise indicated.

\title{
Colour in urban places: A case study of Leicester City Football Club blue
}

PLEASE CITE THE PUBLISHED VERSION

https://doi.org/10.1002/col.22378

PUBLISHER

(c) Wiley

VERSION

AM (Accepted Manuscript)

PUBLISHER STATEMENT

This is the peer reviewed version of the following article: XU, J., 2019. Colour in urban places: A case study of Leicester City Football Club blue. Color Research and Application, 44 (4), pp.613-621, which has been published in final form at https://doi.org/10.1002/col.22378. This article may be used for non-commercial purposes in accordance with Wiley Terms and Conditions for Use of Self-Archived Versions.

\section{LICENCE}

CC BY-NC-ND 4.0

\section{REPOSITORY RECORD}

Xu, Johnny. 2019. "Colour in Urban Places: A Case Study of Leicester City Football Club Blue". figshare. https://hdl.handle.net/2134/38075. 


\title{
Colour in Urban Places: A Case Study of Leicester City Football Club Blue
}

\author{
Jie $\mathrm{Xu}$
}

School of the Arts, English and Drama, Loughborough University, Loughborough, UK

\section{Introduction}

This paper presents an empirical investigation on the process of place-making through colour design not only at local level and a global scale. The guiding research question is how does colour contribute to constructing place identity in urban environments? The research comprises a case study inquiry of the Leicester City Football Club (LCFC), in the United Kingdom that directs the research towards an understanding of how colour functions through architecture in a dynamic urban context.

The case study focuses in the impact of 'colour theming' on place identity. By tracing the Leicester City Football Club colour, blue, the research is an extensive exploration of the various places, for example, including stadium, pubs, retail shops and neighbourhoods, where the Leicester City Football Club blue is on display. Simultaneously, virtual space, such as website, television and social media, is also considered as complementary to visual experience.

The research findings conclude that the construction of place identity through colour can be formed by three aspects: branding, identity and visual culture. In this paper, place identity means the impression of a branded place, the emotional response when attached the place, and interpretation and understanding of a system of images. Constructing the place identity involves colour design as an underpinning and defining activity, based on the notions of identity making and employing a combination of theoretical and practical methods as part of the iterative design process. 


\section{Background}

Football has played an important role within British culture for more than a century in the UK. In many cities, football has ingrained itself into the local culture and history, and parts of life may revolve around it. There is a particular obsession in England which may be because of the sport's history. The English Premier League is the mostwatched sports league in the world. ${ }^{1}$ A list of television broadcasters provides coverage of 102 countries and territories based on the broadcast schedules for 201619. ${ }^{2}$ The football matches are attended by the local fans in the UK but the sports has also become an international attraction via a huge supporter spectrum.

The Leicester City Football Club was founded in 1884 as Leicester Fosse F.C., playing on a field near Fosse Road. ${ }^{3}$ The club won the 2015-2016 Premier League, their first top-level football championship, the whole city became the ground for a huge public celebration of the achievement, witnessing an important historical moment of the city. Since then, the themed colour blue connects object-to-object; place-to-place that makes and enhances the meaning of the successes of the team as well as a sense of pride towards the city. As a prominent visual element, colour is shifting the focus from the infrastructural and material of environment settings to a new-layered interface of urban fabric. The places and space integrate 'blue' narratives about the city's history and culture. It communicates and informs the city readers of the particular colour as a subject rather than an object, committing important element in a sense of place.

\section{A sense of colour place and space}

\section{Stadium}

Leicester City Football Club moved the short distance from Filbert Street to King Power Stadium in 2002, then named Walkers Stadium. Designed by specialist architects Miller Partnership, the seating structure has a robust engineering quality added to a sleek, glazed building fronting the river and containing reception, hospitality and conference suites, all dominated by the team's dark blue. ${ }^{4}$

LCFC's previous ground, Filbert Street, had been home to the club since 1891, but 
further redevelopment would prove expensive following its conversion to being an all-seater stadium in 1994. Eight years later, the club was bought by a Thai-led consortium called Asian Football Investments led by King Power's Chairman Vichai Raksriaksorn. Consequently, the stadium was officially renamed the King Power Stadium in $2011 .^{3}$

In modern urban development, new stadiums have been criticised for their homogenisation. Researchers ${ }^{5,6,7}$ apply Relph's conception of 'placelessness ${ }^{8}$ as the interpretation of stadium. They believe that stadium as a depersonalised site aims to regulate the same behaviour of players and crowds. Moreover, the homogeneity of design and construction ensures a common code, which is predictable and invariable from one place to another. ${ }^{6}$ While the typology of architecture necessarily labels the stadium as a space for sports, however, the new urban arenas are not satisfied with the similarity and stereotypical form. The desire to create iconic structures in the form of sport facilities tends to enhance or change a city's image while also improving the quality of life. $^{9}$

Colour then is considered as an important feature of architecture: graphically makes the stadium different. The use of blue in the King Power Stadium highlights a remarkable visual identity of the site (Figure 1). In the stadium, a standard colour code has been clearly seen in the inclination towards a self-image of the football club through the uniforms, the plastic seats, and the compartment panels and banners. These colour elements eliminate any sign of nature by using synthetic materials for the architectural structure and ground field of the stadium. 


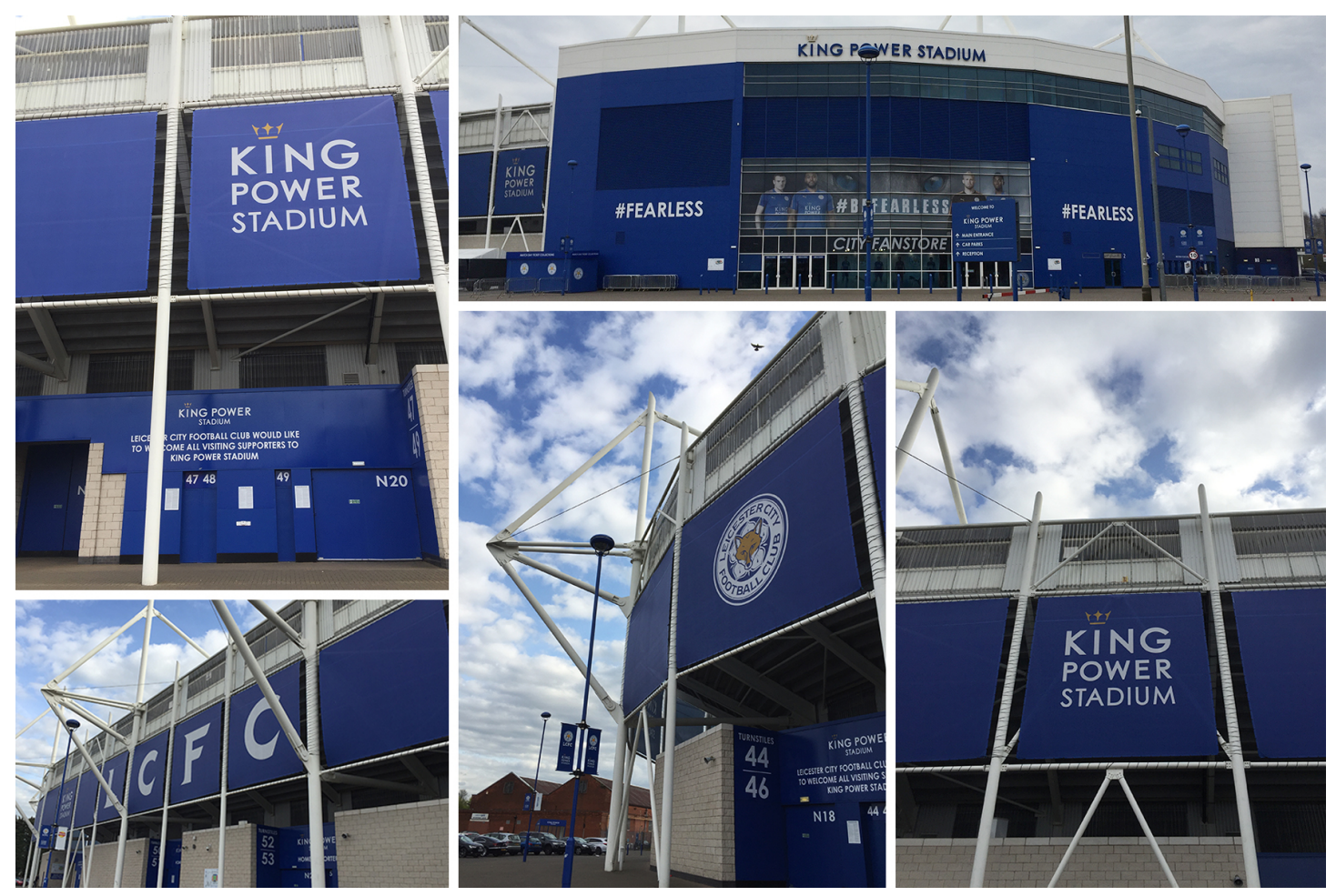

Figure 1. King Power Stadium, Leicester (Photo: XU, 2017)

Simultaneously a historical image of a stadium is part of local culture that serves the purpose of representation in a semiotic sense. The infrastructure and configuration of the stadium provides readable material for decoding and interpretation, whereas colour is involved in a process of abstraction, conceptualisation and symbolisation. Colour provides visual cues not only for identification but also produces visual signifiers to produce new meanings of urban semiotics.

\section{Fanstore}

The second place to be considered is the King Power Stadium Fanstore. In the retail space, various products can be found in relation to LCFC, such as shirts, mascots, accessories, books, souvenirs, calendars and the props for fans (Figure 2). With a wide variety of commodities, the emblems, image of foxes, the checkered patterns, are always associated with the colour blue giving a consistent visual experience of the club. 

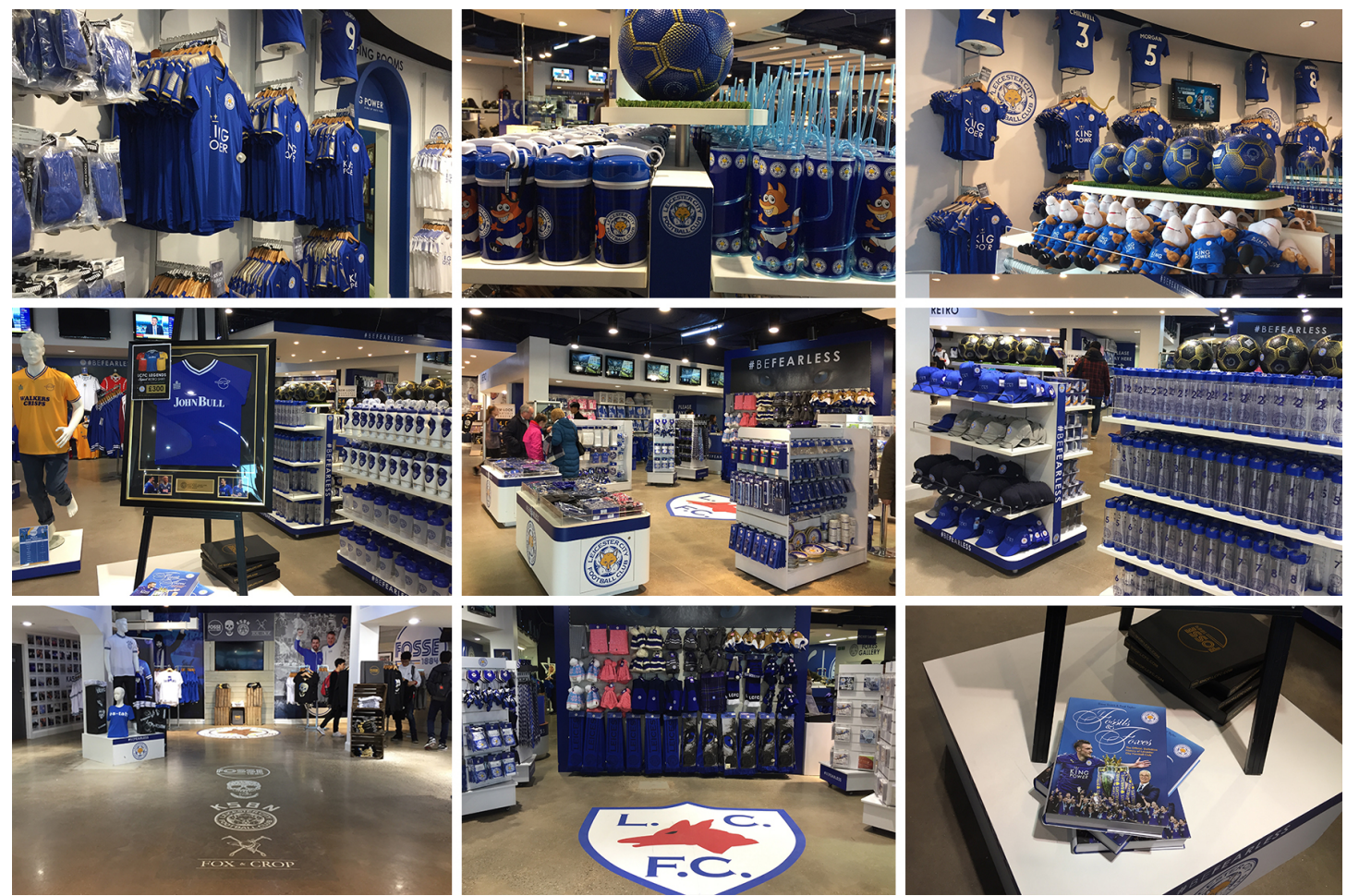

Figure 2. King Power Stadium Fanstore (Photo: XU, 2017)

As the symbols can empower and support whatever happens in the areas of behaviour and communication, ${ }^{10}$ in the sense, purchasing the merchandise in the shop is a consumption of symbols that address economic force driven by the sports culture. Zukin observers that a significant increase of new public spaces intertwining of cultural symbols and entrepreneurial capital. ${ }^{11}$ The fanstores are strategically implementing and practicing a 'symbolic economy', which intends to organise the meaningful representations into commodities. The symbolic economy, as a continual reproduction of symbols and spaces, frames and gives meaning to the change of identity and environment. The integration of corporate identity and place identity fosters the potential market both in sports culture and commercial business, as well as locally and globally.

The visual representation of LCFC symbols relies on the form of emblems, icons, patterns, figures, in additional to colour. A themed colour is not only additional or complementary to the image of the club but also fundamental and essential elements for recognition and identification. Colour is regarded as a resource to provide the symbolic economy socially, materially, and spiritually. ${ }^{11}$ In this sense, the consumption of products rather is the consumption of colour. 


\section{Pubs}

The third scenario is the integration of football culture and pub culture as a unique British urban phenomenon (Figure 3). Most of the pubs and bars in Leicester are decorated with blue flags, blue shirts and banners especially during the Premier League seasons that manifest and constitute a significant 'homely' environment and 'hosting' identity. These visual objects do not only serve the decorative functions to the interior, but also 'embody aspirations and values; they evoke moments of defeat and joy'. ${ }^{12}$
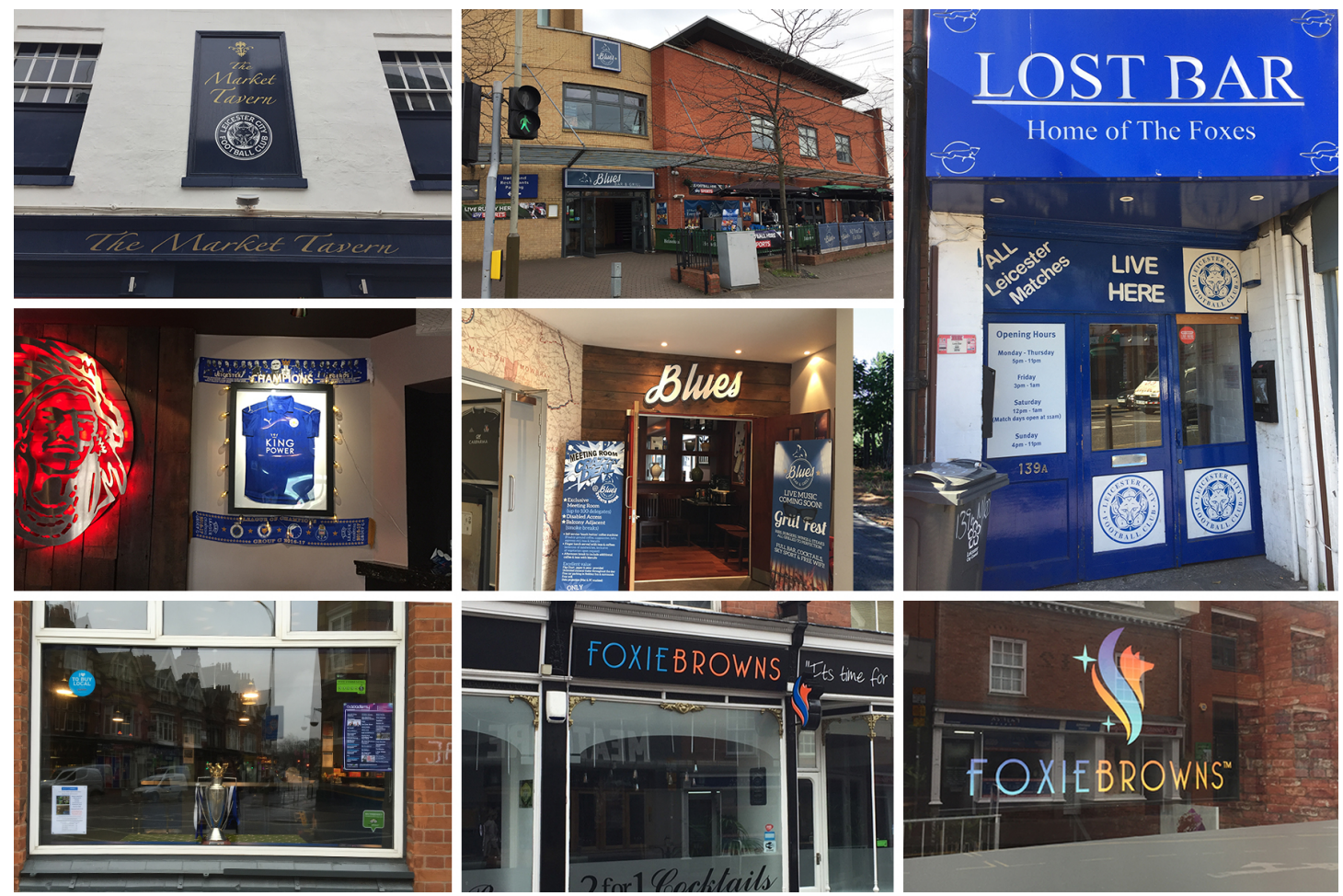

Figure 3. The 'Blue' Pubs in Leicester (Photo: XU, 2017)

Bale suggests stadia are regarded as sacred places, much like a church. ${ }^{2}$ A similar metaphor can be applied to the pubs as chambers, which construct an attachment between supporters and the club. Football creates an opportunity for socialisation, by watching and talking about the matches together in the pubs. It enables supporters to mediate their social behaviours and emotions within the sport community and subgroups. The 'blue' pubs do not only present the individual identity, but also a collective recognition of the social encounters or authority in the city. The blue decorated pubs in Leicester provide a revealing device to distinguish between insiders 
and outsiders and 'heighten people's awareness of, and sensitivity to, their community' ${ }^{12}$.

\section{Murals}

The fourth place are the murals in various locations throughout the city, including: Bath Lane, Kate Street, Tudor Road, St Nicholas Circle, Burnmoor Street, The Magazine, and Newarke Houses Museum (Figure 4). In celebration of LCFC Premier League title wins, the Leicester City Council has commissioned the artworks to give visitors and residents the chance to re-live the memories of the fantastic season and the major achievement of LCFC as they travel around Leicester.
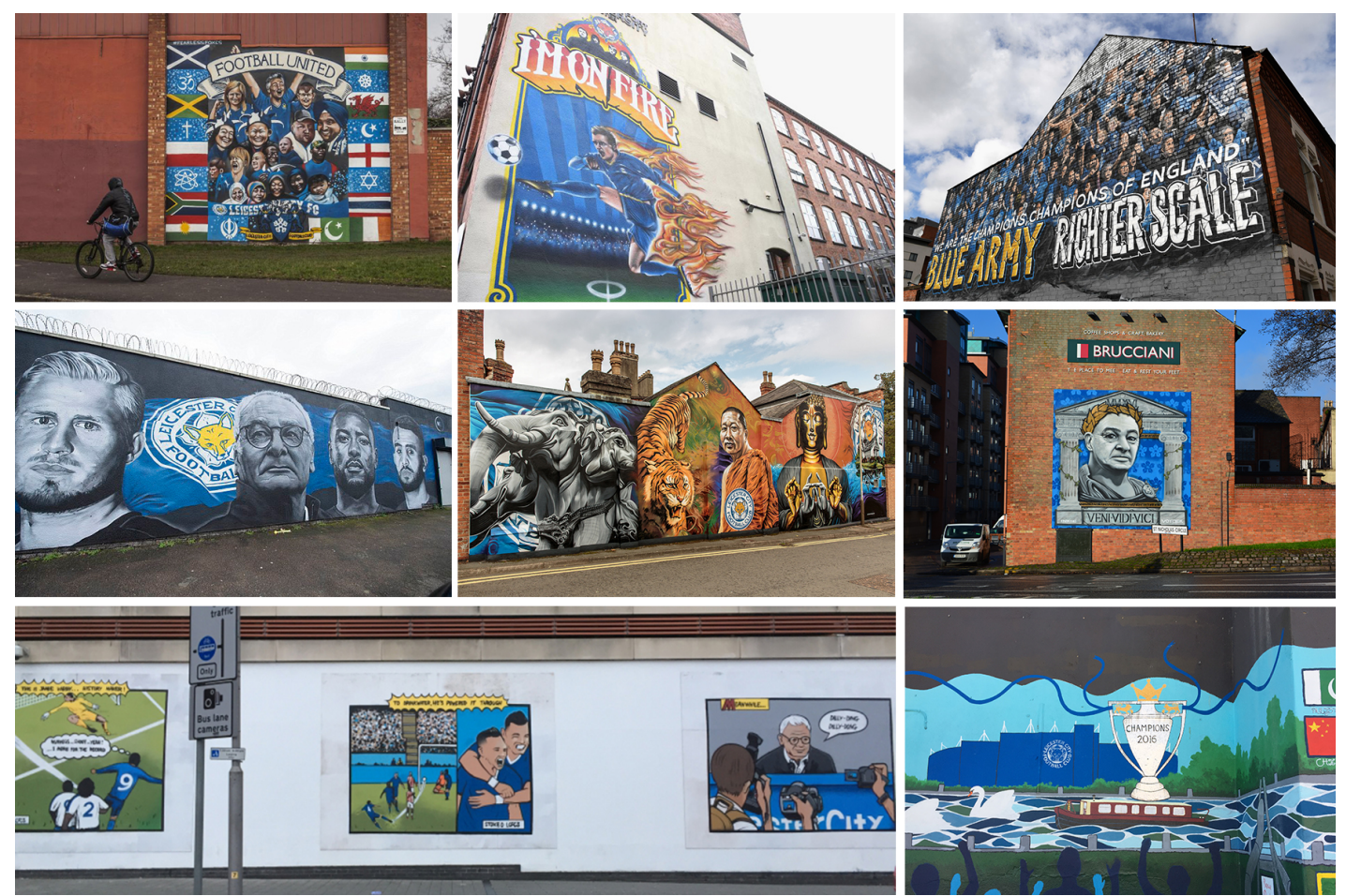

Figure 4. 'Forever Fearless' Murals in Leicester (Photo: XU, 2017)

This local government-sponsored urban project turned the urban zones into themed places with carefully controlled visual information necessary for sustaining a city image for both insiders and outsiders. The urban policy is explicitly engaging with the visual distribution of public space by providing an assemblage of visual communication and symbolic meaning making. The visual presentations on the walls indicate and inform the spectators that what happens and exists with and in the city. 
Although the murals are located in different neighbourhoods of the city, they have been constantly associated with the LCFC particular blue that produces an internal visual code for understanding and sharing a same story of the football club. The blue as the main visual semantic communicates an exclusive symbolic meaning that is superimposed in the visual narrative of the works of the street art. The colour blue functions as the visual cues connecting with places in different locations. The places are isolated from a large urban context, but as part of associated network to be recognisable and understood. Irvine considers 'network society' as a regional site incorporating vast amounts of population mobility, flows of intellectual and material capital, expanding beyond historic and local identity politics. ${ }^{13}$ Indeed, the mural project creates an opportunity for a sports culture expanding the cultural territories and boundaries for involvement in a larger process of socialisation in the city.

\section{Virtual space}

It is obvious that visualisation and visual culture in postmodern society cannot neglect the imagery of virtual space. New digital technologies and media enable a discovery of re-representation in redefining time-space compression. By watching broadcasted live matches, surfing the official club website and interacting with the players via social media, the connection of virtuality requires a highly recognisable visual map for directing and leading to a specific visual domain. The colour blue then provides a comprehensive and effective visual cue to link and orientate cultural territories in a virtual space. Moreover, the mediascapes and technoscapes bring the discussion further into a wider context of virtual space in a global scale.

Currently, the modern football spectacle is not only experienced 'physically' by those at the stadium, but also by millions of viewers watching the event live, via satellite television and the internet, such as online streams and the iPhone's 'Sky Go' app. ${ }^{14}$ These digital media are representative of telling and retelling what take place during the matches that reinforce the memory of every moment. For example, according to the attendance statics of Premier League 2014-2015, a total sum of attendance of overall matches of LCFC is 1,296,544 comprising 602,165 home matches and 694,379 away matches. ${ }^{15}$ However, the league was broadcasted in 730 million homes, where it reached 3 billion people. ${ }^{16}$ This demonstrates that the audiences who 
experience the match virtually are considerably larger than those watching at King Power Stadium.

The interaction between virtual audiences and football events can be captured by the players' performance as well as the live attendance behaviours and emotions. Thus, the virtual audience of sports arguably forms a much large 'imagined community' rather than the supporters in local pubs as discussed earlier. The group of LCFC supporters can be included people who come from any regions across the countries and regardless of the ethnic, gender, age, colour of skin, social class and cultural preference. The democratisation of the sports becomes a significant phenomenon to reflect the process of globalisation. When the team achieved the title of Premier League, an emphasis on the club becomes internationally exposed, representing a British identity in a global context. As Turner further suggests, the notion that it is not space or place which captures fandom best, but it does offer a telling contribution to the sociology of football fandom. ${ }^{14}$ It is also important to appreciate the changing nature of fan participation because of various new technical, social, cultural or political processes.

As the differences between the passive and participatory, and the physical and the visual collide, so too does the difference between geography and technology where, in a sense, the live mediated technological event has displaced the distinctiveness of the geographical live physical presence of space and place. ${ }^{17}$ Indeed, the emerging force of digital techniques and new media changes the sports landscape dramatically and brings an opportunity for a specific sports culture beyond the constraint of the physical structures and configurations. The emblems and colours of the club appearing on the screen claims and reclaims the territory of symbolic football space. In contrast to physical place, space as practical place allows more situation, mobility and temporisation. ${ }^{18}$ The property of virtual space is an experiential orientated function to transform and modify the experiences and meanings from the convention of actuality to a virtual imagination.

In the process of constitution of spatial experiences, a concentration on visual presentation is considered as one of the essential elements. The blue of LCFC has been used in all its publication, press, website and social media through corporate identity scheme, branding and graphic design to enhance the user experience. Central 
to the club identity and image, cyber space thus creates another blue regime for the reinterpretation or reimaging of identity and belonging. ${ }^{14}$

By analysing these places, it realves the common application of distinctive and consistent dominant colour. The symbolic meaning of colour is derived from the club identity which influence four major areas of activities: 'Products/Services; Environments; Information; and Behaviour' ${ }^{19}$ at multiple levels in the social life of the city. This frames a hierarchy of symbolic place identity related to different layers of cultural meaning in the following. First, the stadium as a metaphor of 'home' represents a city rather than a sports site. The symbolic meaning of the stadium thus is implicit of belonging to a place and a city as part of urban culture. Second, regularly participating in pubs to support the team also is considered a symbolic phenomenon in local culture for public. The pubs as 'church' or 'chamber' are vital place gathering and aggregating the members of same cultural group. Third, the products selling in the souvenir shop and tourist centre are the consequence of a process of symbolisation, and commodification of football culture. Fourth is the virtual space is created not only for the local supporters and fans to interact with but also to facilitate and promote the club to an international imaged community and potential market in a local-global context.

\section{Place identity through colour}

\section{Colour and branding}

The emblems are consistently associated with the colour blue throughout the long history of the LCFC. That is why in local terms, the club is also known as 'The Blues'. Today the legend of blue continues, with the club acquired by a Thailandbased corporation, The King Power International Group, in 2010. Since the 2011-12 season, the name of the home ground of the LCFC has been changed to The King Power Stadium. The corporate logo of the company coincidentally fits into the colour context of the club. Consequently, the company logo, stadium logo, and club emblem standardise a unified colour code that enhances the discernibility of Club's visual identity (Figure 5). 


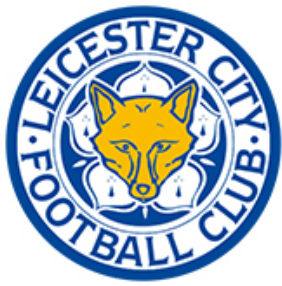

Figure 5. King Power International Group logo, King Power Stadium logo and Leicester City Football Club logo (Source: www.lcfc.com)

By integrating the corporate identity with the stadium identity, the King Power International Group successfully adopted LCFC as one of its important 'house' brands under the 'mother' corporation. The changes though do not cause any disruption and damage to the original image of the club. Colour combinations particularly enable the audience to quickly grasp the message of the logo rather than other graphic elements. The attention value of the blue colour provides distinctiveness and character to the identity through its colour scale. More importantly, it achieves the goal of maintaining the consistency and continuity of blue as part of the club's heritage and culture.

As an ensemble of the club corporate identity, the blue is registered as colour identity, and the dominant colour becomes part of the club's narrative, representing its players, investors and supporters. Colour does not only create distinctiveness for identification and classification, but also can treated as an absolute and permanent signification. ${ }^{20}$ The semiotic sense of football places has been greatly influenced and benefited from new investment from entrepreneurs, supporting from local government and attention from medias.

Renaming the arena King Power Stadium obviously reflects the economic power through a process of place-branding. The process is applying 'the branding procedure as applied to commercial products' ${ }^{21}$ to particular place with its commercial marketing and advertising activities. The physical place of stadium embodies the visible signs and corporate logos that urge consumption and identify the corporation associated with the historical values of the club. By inserting and consolidating the corporate identity into an exciting sport arena, it forms an integrated branded place. While the football culture involves the social life of Leicester, the colour symbolisation as a process of sharing meaning contributes to the place identity at 
different levels of urban environments, disseminated and displayed in various locations of city.

\section{Colour and loyalty}

With regard to the identity issue in sports culture, three identities are worthy of consideration: player, investor and supporter. The case of LCFC demonstrates how colour involves and accommodates the three identities into one unified identity. The blue colour furthers the notion of bonding and creating an imagined community based on the football culture.

First is the identity of the player, as an athlete and public figure. The participation in sports is not separated from social activities that involve a process of socialisation through identity formation process. The identities of LCFC players reflect a significant connection of multiple and diverse processes in contemporary sport context. The first team of LCFC as announced in 2016-2017 season, comprised 33 players from 15 countries and regions. The ethnic identity of players reflects how the team has transformed the game and created a global connectivity and growing consciousness of the world as a single place. ${ }^{22}$ Simultaneously, by wearing the same uniforms, the foreign players are embraced into the blue community that reshapes and constitutes an accepted diverse image to represent a local football club.

Second, the identity of King Power International Group connotes an economic power involved in sports culture. The corporation negotiates deals that promote their interests, increase their power and create a positive image of themselves as 'global citizens and leaders'. ${ }^{7}$ As discussed previously, the investor incorporates its brand identity to the stadium as part of the club's identity, especially with colour. The changes of name and logo of the stadium do not only endorse and claim an authority of the club, but also to a large extent it endorses a branding practice in sports. It also suggests a football symbol has been charged with extra and additional economic and commercial meaning by the investors and sponsors. By associating products and service with the football club, colour becomes an important assertion and intervention to create more business opportunities in the commercial market. 
Third, supporters develop an identity and an affinity towards a particular club that forms a community. Turner suggests that the fans are conscious that they are part of a broader 'imagined community' of fellow supporters. ${ }^{14}$ The focus on the nature of fandom of LCFC reflects a diverse and complex ethnic, social class, and cultural subgroup. Encompassing these considerations, it challenges a conventional geographic sense of boundary of the football culture. As a result, it provides an opportunity for adopting a strong collective identity - which could be referred to as an 'overriding identity' - permeates all aspects of the individual's life. ${ }^{12}$ Colours have proved especially potent in the display elements of identity; notably, as they appear on logos and jerseys, but also on other merchandise sold by the club. ${ }^{23}$ Therefore, the identity of LCFC supports associate with blue as a distinctive visual signifier through its established conventional meanings.

Thus it reveals that the players, investors and supporters of LCFC consolidate and constitute their shared identity through colour symbolism - 'invented blue culture'. Olins believes the symbols and colour of identity on the one hand encapsulate and make vivid a collective sense of belonging and purpose, on the other hand, encourage the audience and customers loyalty ${ }^{19}$.

Colour has the capacity to integrate with different identities as an accepted and recognisable public image. LCFC' blue produces the conventional meanings that are regarded as a psychic function, which depends on identification, and implies a sense of belonging. Nevertheless, a loyalty to LCFC is not only limited within a football culture, it also possibly expands the emotional attachment to the city and even the country at a large scale, as the club representation reflects a hierarchy of identities. For example, from the conversation with a Chinese restaurant owner, he believes by wearing the blue kit it is an indication of cultural and social self-adaption to the local community. Regular attendance and participation at King Power Stadium is a means of socialisation and localisation to him, which initiates the creation of an emotional bond to Leicester as the home to which he immigrated and resettled.

\section{Colour in visual culture}

A historical image of a club is part of local culture that serves the purpose of representation in a semiotic sense. The infrastructure and configuration of the sport 
places and space provides readable material for decipherment, decoding and interpretation, whereas the colour involves a process of abstraction, conceptualisation and symbolisation. Colour provides visual cues is not only for identification but also produces visual signifiers to produce the urban semiotics. LCFC's blue rewrites the local visual culture and challenges the meaning of colour symbolism.

The impact of colour on local visual culture can be reflected in the changing of colour preferences. For example, during the celebration of the championship win, one of the wedding retailers in Highcross Street, Leicester, featured a blue wedding gown in their window display. Shifting from white to blue, the colour symbolism of wedding has changed conventional meaning of association, which is greatly rooted in a specific local cultural context. Gage points out that it is important to translate colour symbolism into modern psychological language. The literature meaning of colour symbols forms an explanatory coherence of understanding in visual culture. ${ }^{24}$ This is also the reason to believe colour has the capability to confront and reconstruct new meanings in the way of seeing.

Tajfel \& Turner reveal that social categorisation, according to some trivial criteria such as the 'blue' or the 'red' group, is sufficient to make people feel, think and act as a group member. ${ }^{25}$ Thus, colour evidently creates a visual distinction in the identification process. Identifying ourselves or others is a matter of meaning, and meaning always involves interaction: agreement and disagreement, communication and negotiation. ${ }^{26}$ The blue colour of LCFC as a result of social convention has a stable and accepted meaning in general. The mutual understating and shared meanings are even engraved in the history of Leicester, which can be part of collective memory and heritage of the city.

Moreover, Taylor conceives of social movements as discursive communities held together not only by common action and bonds of solidarity, but by identities, symbols, shared identity discourse, and practices of everyday life. ${ }^{27}$ This suggests that the social identification requires a medium for showing, sharing and acting. The symbols and colours are appropriated for the notion, which has been used widely in the unification of social class, ethnic and cultural groups, especially in Leicester's diverse society. 
Therefore, the 'blues' share common interests to become members of a large community that spans beyond the frame of local and global. A positive attitude towards respecting and appreciating others has been cultivated as a shared value and belief in Leicester. The blue does not signify the exclusion nor create a barrier between people; rather, the colour promotes tolerance and embraces multiple identities for the homogeneity of collective identity.

\section{Conclusion}

The findings of the case study have implications for research and design on place identity through colour. The study revealed that 1) more than one place share the same colour identity 2) place identity is incorporated with corporate identity 3) place identity associated with certain sport culture. It suggests that the exploration of place idenity should not be limited to a particular place. In a 'networked' urban environment, it is more important to examine the structral relationship between place and place as well as place and space. This relationship is not only geographical, but also contains economic and cultural premises, because these contexts provide the necessary and decisive resources for local identity.

Place identities are achieved by emphasising colour of the physical place and virtual space through branding, visual culture and identities. The three aspects form structural knowledge to inform designers in formation, identity communication. What the case reveals is that place identity is multifaceted and complex. Therefore, the basis of place identity formation, management, and dissemination based on establishing a culture needs to be appraised.

The presence of LFCF blue urges an attention to reimage and reimagine the city in a dominant urban culture that suggests an opportunity and initiative for urban design. Colour contributes significantly to create a clear territoriality and the place identity. Colour represents idealised aesthetics and preferences interwoven with the existing urban fabric and visual representations. Colour is given meanings to be used in sociocultural lives through the historical and cultural situated process of place-making for sports. 


\section{References}

1. Ebner S. History and time are key to power of football, says Premier League chief. https://www.thetimes.co.uk/article/history-and-time-are-key-to-powerof-football-says-premier-league-chief-3d3zf5kb35m Published 2013. Accessed August 7, 2017.

2. PremierLeague. Broadcast Schedules. https://www.premierleague.com/broadcast-schedules Published 2017. Accessed August 8, 2017.

3. Leicester City Football Club Official website. LCFC. https://www.lcfc.com/club/history. Accessed August 7, 2017.

4. Taylor M. The Quality of Leicester. Leicester: Leicester City Council; 2016.

5. Bale J. Sport, Space, and the City. Caldwell: The Blackburn Press; 1993.

6. Nielson NK. The Stadium in the City: A Modern Story. In: Bale J, Moen O, eds. The Stadium and the City. Hartnolls: Keele University Press; 1995:21-44.

7. Coakley J, Pike E. Sports in Society: Issues and Controversies. London: McGraw-Hill Education; 2014.

8. Relph E. Place and Placelessness. London: Pion; 1976.

9. Rosentraub MS. Major League Winners: Using Sports and Cultural Centers as Tools for Economic Development. London: CRC Press; 2010.

10. Nas PJM, Samuels A, eds. Hyercity: The Sybolism Side of Urbanism. London: Kegan Paul Limited; 2006.

11. Zukin S. The Cultures of Cities. Oxford: Blackwell Publishing; 1995.

12. Guibernau M. Belonging: Solidarity and Division in Modern Societies. Cambridge: Polity Press; 2013.

13. Irvine M. The Work on the Street: Street Art and Visual Culture. In: Heywood I, Sandywell B, eds. The Handbook of Visual Culture. London: Bloomsbury; 2011:235-280.

14. Turner M. Football Fandom in Late Modernity: Alternative Space and Places of Consumption. In: Dashper K, Fletcher T, McCullough N, eds. Sports Events, Society and Culture. London: Routledge; 2015:40-52. 
15. WorldFootball. Premier League 2014/2015-Attendance. http://www.worldfootball.net/attendance/eng-premier-league-2014-2015/1/ Published 2017. Accessed August 8, 2017.

16. Elder R. The English Premier League's viewership drop spells danger for the future of sports on TV. http://uk.businessinsider.com/heres-what-the-englishpremier-league-viewership-drop-means-for-the-future-of-live-sports-2017-1 Published 2017. Accessed August 7, 2017.

17. Redhead S. Post-Fandom and the Millennial Blues. London: Routledge; 1997.

18. de Certeau M. Spaces and Places. In C. Doherty, ed. Situation. London: MIT Press; 2009:118-120.

19. Olins W. Corporate Identity. London: Thames and Hudson; 1989.

20. Arnkil H. Colour in the Visual World. Helsinki: Aalto University publication; 2013.

21. Julier G. The Culture of Design. 3rd ed. London: Sage; 2014.

22. Robertson R. Globalisation: Social Theory and Global Culture. London: Routledge; 1992.

23. Ranc D. Foreign Players and Football Supporters. Manchester: Manchester University Press; 2012.

24. Gage J. Color and Culture: Practice and Meaning from Antiquity to Abstraction. Berkeley: University of California Press; 2014.

25. Tajfel H, Turner JC. An Intergrative Theory of Intergroup Conflict. In: Worchel S, Austin WG, eds. The Social Psychology of Intergroup Relations. Chicago: Nelson-Hall Publishers; 1979:33-53.

26. Jenkins R. Social Identity. London \& New York: Routledge; 1996.

27. Taylor V. Social Movement Participation in the Global Society: Idenity, Networks and Emotions. In: van Stekelenburg J, Roggeband M, Klandermans $\mathrm{B}$, eds. The Changing Dynamics of Contention. Minneapolis: University of Minnesota Press; 2013:37-58. 